\title{
Bone marrow cell-induced protection of the human myocardium: Characterization and mechanism of action
}

\author{
Vien Khach Lai, MD, José Linares-Palomino, MD, PhD, Bernardo Nadal-Ginard, MD, PhD, and \\ Manuel Galiñanes, MD, PhD, FRCS
}

\begin{abstract}
Objectives: The mechanism of the putative beneficial effect of myocardial transplantation of bone marrow cells remains unclear. We studied the protective properties of bone marrow cells on the human myocardium and investigated the underlying mechanism.
\end{abstract}

\begin{abstract}
Methods: Bone marrow cells and the right atrial appendage were obtained from patients undergoing elective cardiac surgery. Myocardial slices were subjected to 90 minutes of simulated ischemia/120 minutes of reoxygenation at $37^{\circ} \mathrm{C}$ following various protocols. Tissue injury was assessed by creatine kinase released into the media during the reoxygenation period, and myocardial necrosis and apoptosis were determined by propidium iodide and terminal deoxynucleotidyl transferase-mediated dUTP nick end labeling (percent of aerobic control).
\end{abstract}

Results: Autologous unfractionated bone marrow cells significantly reduced myocardial injury. Maximal protection was obtained with $5 \times 10^{6}$ autologous cells $\left(\sim 1.5 \times 10^{5}\right.$ cells $/ \mathrm{mg}$ wet myocardium $)$ that caused a reduction in creatine kinase release and cell death by necrosis and apoptosis of $70 \%$ to $80 \%$. Allogenic bone marrow cells were as protective as the autologous cells and their effect was unaffected by prior frozen storage or culturing. Similar myocardial protection was also attained when bone marrow cells were present only before or during ischemia, or during reoxygenation, a benefit that was comparable with that of ischemic preconditioning. Conditioned media by the bone marrow cells was sufficient to induce protection, which was abolished by the selective insulin-like growth factor-1 receptor blocker PQ401.

Conclusions: Bone marrow cells possess potent myocardial protective properties that are triggered by a secreted factor or factors and mediated by insulin-like growth factor-1 receptor. These results have important clinical implications for the therapeutic use of bone marrow cells in ischemic heart disease and for the design of future clinical studies. (J Thorac Cardiovasc Surg 2009;138:1400-8)

\section{Supplemental material is available online.}

Experimental data have demonstrated that cell therapy has the potential to repair the damaged myocardium. This expectation and the clinical need for an effective treatment to reduce the injury sustained during an acute myocardial infarction and to repair the failing heart have accelerated the performance of clinical trials mainly using bone marrow cells (BMCs), even before the underlying mechanisms have been elucidated. However, the outcomes of the randomized clinical trials

From the Cardiac Surgery Unit, Department of Cardiovascular Sciences, University of Leicester, Leicester, United Kingdom.

Funded by the Government of Vietnam and Consejeria de Salud de la Junta de Andalucia, Spain (EF-06/2007).

Received for publication March 17, 2009; revisions received June 8, 2009; accepted for publication July 6, 2009; available ahead of print Aug 19, 2009.

Address for reprints: Manuel Galiñanes, MD, PhD, FRCS, Cardiac Surgery Unit, Department of Cardiovascular Sciences, University of Leicester, Glenfield Hospital (Clinical Science Wing), LE3 9QP Leicester, United Kingdom (E-mail: mg50@ le.ac.uk).

$0022-5223 / \$ 36.00$

Copyright (c) 2009 by The American Association for Thoracic Surgery doi:10.1016/j.jtcvs.2009.07.013 have been controversial. ${ }^{1-3}$ It has been argued that differences among the cell composition and manipulation of BMCs may be responsible for the observed differences among some of these studies. ${ }^{4}$ All this has prompted investigators to go back to the laboratory to clarify what BMCs can do, to identify the cellular/molecular mechanisms involved, and also to define the best modalities of application.

Beside the regenerative capacity, BMCs can act through a paracrine mechanism to increase angiogenesis and to reduce cell death. ${ }^{5,6}$ Recently, our laboratory has demonstrated that BMCs reduce cell necrosis and apoptosis of the human myocardium ${ }^{7}$ in an acute in vitro nonperfused model, suggesting that the effect could be due, at least in part, to a direct effect of the BMCs on the myocardium and may not necessarily be a consequence of improved vascularity and blood supply. One of the mechanisms that may be responsible for the BMC-induced benefit on the ischemic myocardium is through a paracrine action by reducing cell death and/or by preservation and activation of resident stem cells. Hence, the aims of the present studies were (1) to investigate the mechanism of BMC-induced myocardial protection and (2) to identify whether the manipulation of BMCs, the time of their administration, and the cell type influence this beneficial effect. 

Abbreviations and Acronyms
$\mathrm{BMC}=$ bone marrow cell
$\mathrm{CK}=$ creatine kinase
DAPI $=4^{\prime} 6$-diamidino-2-phenylindole
ELISA $=$ enzyme-linked immunosorbent assay
IGF $=$ insulin-like growth factor
IGF-1R = insulin-like growth factor-1 receptor
IP $\quad=$ ischemic preconditioning
$\mathrm{I} / \mathrm{R} \quad=$ ischemia/reoxygenation
$\mathrm{KHH}=\mathrm{Krebs} /$ Henseleit/Hepes

\section{METHODS}

\section{Study Patients}

The right atrial appendage from patients aged 44 to 82 years and undergoing elective heart surgery for coronary bypass or aortic valve replacement was obtained before the initiation of cardiopulmonary bypass. These patients were routinely receiving cardioactive drugs according to standard prescriptions (B-blockers, angiotensin-converting enzyme inhibitors, statins, and aspirin or clopidogrel). Ethical considerations prevented us from discontinuing the drugs more than 24 hours before the operation; however, previously we have observed (unpublished data) that these medications have no effect on the tolerance of the atrial myocardium to ischemia and its response to ischemic preconditioning. Patients with atrial fibrillation, cancer, diabetes, poor left ventricular function (ejection fraction $<30 \%$ ) or with additional surgical procedures or those being treated until the initiation of surgery with opioids, catecholamines, or the adenosine triphosphate potassium-channel opener nicorandil, were excluded from the study. The study was conducted according to Declaration of Helsinki principles and approval was obtained from the local ethics committee. All participants provided written consent.

\section{Experimental Preparation}

The experimental preparation has been previously described and fully characterized. ${ }^{8}$ After resection, atrial samples were immediately immersed in cold $\left(4^{\circ} \mathrm{C}\right) \mathrm{Krebs} / \mathrm{Henseleit} / \mathrm{Hepes}(\mathrm{KHH})$ medium containing (in micromoles per liter) $\mathrm{NaCl} \mathrm{118,} \mathrm{KCl} 4.8, \mathrm{NaHCO}_{3} 27.2, \mathrm{KH}_{2} \mathrm{PO}_{4} 1, \mathrm{MgCl}_{2} 1$, $\mathrm{CaCl}_{2}$ 1.25, glucose 10 , and Hepes 20, with a pH of 7.4. Tissues were immediately sectioned with a skin-graft blade (Swann-Morton Ltd, Sheffield, United Kingdom) to slices of 30- to 50-mg weight and 300- to 500- $\mu \mathrm{m}$ thickness. After this, myocardial sections were equilibrated under normothermic aerobic conditions $\left(95 \% \mathrm{O}_{2} / 5 \% \mathrm{CO}_{2}\right)$ for 50 to 60 minutes and then subjected to 90 minutes of simulated ischemia at $37^{\circ} \mathrm{C}$, obtained by continuously bubbling the media with $95 \% \mathrm{~N}_{2} / 5 \% \mathrm{CO}_{2}$ in the absence of glucose and at $\mathrm{pH}$ of 6.8 , followed by 120 minutes of reoxygenation.

For the induction of ischemic preconditioning (IP), myocardial slices were subjected to 5 minutes of ischemia followed by 5 minutes of reoxygenation before induction of the 90 -minute ischemic period. ${ }^{9}$

\section{Aspiration and Preparation of BMCs}

Under general anesthesia and before initiation of cardiac surgery, bone marrow $(50-80 \mathrm{~mL})$ was aspirated from the patient's iliac crest. Fresh BMCs were separated by density centrifugation with Lymphoprep solution (AXIS-SHIELD PoC AS, Oslo, Norway).

Some cells were cultured in GlutaMAX media (Gibco; Invitrogen Corporation, Carlsbad, Calif) containing 10\% fetal bovine serum (HyClone, Logan, Utah) plus penicillin and streptomycin at concentrations of 100 $\mathrm{IU} / \mathrm{mL}$ and $100 \mu \mathrm{g} / \mathrm{mL}$, respectively (Lonza, Basel, Switzerland) for 7 days in $5 \% \mathrm{CO}_{2} / 95 \% \mathrm{O}_{2}$ at $37^{\circ} \mathrm{C}$. After this, all the cells in the culture were collected and resuspended in $\mathrm{KHH}$ solution for their experimental use.

For freezing, the fresh cells were resuspended in fetal bovine serum containing 10\% dimethyl sulfoxide (Sigma-Aldrich, Dorset, United Kingdom) and stored at $-80^{\circ} \mathrm{C}$ in cryovials overnight, then transferred to liquid nitrogen, where they were kept until used. For experimental use, cells were thawed, washed, and resuspended in KHH solution.

BMC viability was assessed by the absorption of Trypan blue (SigmaAldrich) in which cells that did not exclude the dye and stained with dark blue were considered as dead.

\section{Assessment of Tissue Injury}

Tissue injury was assessed by measurement of creatine kinase (CK) release into the media during the reoxygenation period. CK was measured by the enzyme-linked immunosorbent assay (ELISA) method with a plate reader (Benchmark, Bio-Rad Laboratories, Hercules, Calif) using a commercial CK assay kit (30-3060/R2; Abbott Laboratories, Kent, United Kingdom) and expressed as international units per milligram of wet tissue

\section{Assessment of Cell Death}

At the end of the experimental protocol, to assess necrosis, we incubated tissues for 15 minutes at room temperature with $20 \mu \mathrm{g} / \mathrm{mL}$ propidium iodide (Sigma-Aldrich). Muscles were fixed with $4 \%$ paraformaldehyde and frozen sections were then cut at $7-\mu \mathrm{m}$ thickness.

To assess apoptosis, the slides were stained with fluorescein isothiocyanate employing terminal deoxynucleotidyl transferase-mediated dUTP nick end labeling technique (Roche Diagnostics, Penzberg, Germany). A negative control, obtained by not adding the enzyme solution, was performed every time.

To distinguish the total number of nuclei, myocardial sections were counterstained with $1 \mu \mathrm{g} / \mathrm{mL} 4^{\prime}$ 6-diamidino-2-phenylindole (DAPI, Molecular Probes, Eugene, Ore) for 1 minute and mounted them with anti-fade solution (Prolong Antifade kit, Molecular Probes, Eugene, Ore).

An Axiovert $200 \mathrm{M}$ fluorescent microscope (Carl Zeiss, Göttingen, Germany) at $40 \times$ magnification was used to assess necrosis and apoptosis At least 10 fields per section were examined for each experiment. Propidium iodide and fluorescein isothiocyanate-labeled nuclei were detected by the Cy3 and enhanced green fluorescence protein channels, respectively, whereas DAPI labeling was detected by the DAPI channel. Only the necrotic or apoptotic signals coinciding with DAPI were considered true events. The National Institutes of Health Image software (Scion Corp, Frederick, Md) was used to determine the total events for each field. To avoid the inclusion of artifacts, we counted only signals with areas greater than $16 \mu \mathrm{m}^{2}$.

\section{Assessment of Insulin-Like Growth Factor (IGF)-1 and IGF-2}

ELISA method was used to analyze the concentration of IGF-1 and IGF2 in the conditioned media by employing human IGF-1 detection kit (R\&D, Minneapolis, Minn) and human IGF-2 detection kit (Biosupply, Norwich, Norfolk, United Kingdom) as described by the manufacturers. The minimal detection limit of the procedure was $62.5 \mathrm{ng} / \mathrm{mL}$ for IGF- 1 and $40 \mathrm{ng} / \mathrm{mL}$ for IGF-2.

\section{Study Protocols}

In each study, myocardial slices ( $n=6 /$ group in each study, unless indicated) were randomly allocated to different groups. The right atrial appendage from each donor supplied sufficient muscle slices for all the groups in every study, so that the number of myocardial slices used in each group represents the number of donor patients. Some muscles were aerobically incubated for the whole experimental time serving, as time-matched aerobic controls, and others subjected to 90 minutes of simulated ischemia plus 120 minutes of reoxygenation alone served as ischemic controls. Fresh 
autologous BMCs were used in all studies. In addition, allogenic, cultured, and frozen BMCs were also used in study 3 . The studies were sequentially carried out as described below:

Study 1: To study the most effective BMC dose to induce myocardial protection. To find out the number of BMCs required to obtain maximal protection, we coincubated different doses of cells $\left(0.5,1,5\right.$ and $10 \times 10^{6}$ cells/preparation) with the myocardial slices during ischemia/reoxygenation (I/R).

Study 2: To determine the potency of BMCs and whether the time of administration influences myocardial protection. Fresh autologous BMCs $\left(5 \times 10^{6}\right.$ cells/preparation $)$ were coincubated with atrial myocardial slices during ischemia, during reoxygenation alone, or during both times (throughout) and compared with the effect of IP.

Study 3: To investigate whether the source and the manipulation (culture, freezing) of BMCs affect their protective effect. Because the study on the manipulation of BMCs would require the use of allogenic cells, it was necessary to identify first whether the source of cells has an influence on the degree of protection. To this end, we incubated myocardial slices during I/R with fresh autologous and fresh allogenic BMCs $\left(5 \times 10^{6}\right.$ cells/preparation $)$. Additionally, we incubated myocardial slices during $\mathrm{I} / \mathrm{R}$ with fresh autologous BMCs and with allogenic cells cultured for 7 days or frozen for 1 to 9 weeks.

Study 4: To investigate whether BMCs can precondition the myocardium. BMCs were coincubated with the myocardial slices for different time periods $(10,20$, and 30 minutes) before $\mathrm{I} / \mathrm{R}$, and their antiischemic effect was compared with the one obtained with IP. To reduce the possibility that the concentrations of BMCs could play a role, particularly with the shorter periods of co-incubation, we selected a dose of $10 \times 10^{6}$ cells/preparation for this study.

Study 5: To investigate whether the myocardial protection induced by BMCs is mediated by secreted factor(s). BMCs $\left(10 \times 10^{6}\right.$ cells/preparation) were incubated in $10 \mathrm{~mL} \mathrm{KHH}$ solution under aerobic condition for 30 minutes. The conditioned media (supernatant) was then obtained and coincubated with myocardial slices for another $30 \mathrm{~min}$ before I/R. For comparison, the effect of BMCs $\left(10 \times 10^{6}\right.$ cells/ preparation), also coincubated with the muscles for the same time period, and that of IP were studied.

Study 6: To elucidate whether IGF-1 receptors (IGF-1R) are mediating the protection induced by BMCs. IGF-1 is produced by BMCs and both IGFs (IGF-1 and IGF-2), whose biological activity is mediated mainly through IGF-1R, have been shown to induce cardioprotection. ${ }^{10-14}$ To investigate whether the obtained protective effect of BMCs is mediated by IGF-1R, we incubated atrial myocardial slices for 30 minutes with conditioned media, obtained from the culture of $10 \times 10^{6}$ $\mathrm{BMCs}$ for 30 minutes, before I/R. Experiments were performed in the presence of various concentrations $(0,1.5,15$, and $150 \mu \mathrm{mol} / \mathrm{L})$ of the specific IGF-1R blocker PQ401 (Sigma-Aldrich) that directly inhibits autophosphorylation of the kinase domain of the receptor. ${ }^{15}$

In additional studies, the concentration of IGFs secreted into the media by $10 \times 10^{6} \mathrm{BMCs}$ was determined after 10,20 , and 30 minutes of incubation ( $n=6 /$ group). To examine whether the observed benefit from BMCs is mediated by the IGFs present in the media, we incubated atrial myocardial slices with IGF-1 at the concentration of $62.5 \mathrm{ng} / \mathrm{mL}$ and IGF-2 at the concentration of $40 \mathrm{ng} / \mathrm{mL}$ (both from Sigma-Aldrich) alone and in combination for 30 minutes before I/R. These concentrations represented the minimal detected levels in the BMCs-conditioned media by ELISA.

Study 7: To investigate whether $\mathrm{CD}{ }^{+} 3^{+}$cells are responsible for the myocardial protection induced by BMCs. To identify whether $\mathrm{CD} 133^{+}$cells, a subset of BMCs that have been used in clinical trials for cardiac repair, ${ }^{16-18}$ are responsible for myocardial pro- tection induced by BMCs, we incubated atrial myocardial slices $(\mathrm{n}=$ 5/group) with autologous $\mathrm{CD}_{133^{+}}$and $\mathrm{CD} 133^{-}$cells for 30 minutes before I/R. CD133 ${ }^{+}$cells were isolated using antibody-magnetic beads (Miltenyi Biotec, Bergisch Gladbach, Germany). After that, the percentage of $\mathrm{CD}_{133^{+}}$in the selected cell population was determined. The $\mathrm{CD} 133^{+}$and CD133- cells used in each preparation were those obtained from $10 \times 10^{6}$ BMCs. In addition, myocardial slices were also subjected to an identical protocol using unfractionated BMCs $\left(10 \times 10^{6}\right.$ cells $)$.

\section{Statistical Analyses}

Data are expressed as mean \pm SEM. Values were obtained after subtracting the corresponding time-matched aerobic control values. One-way analysis of variance followed by the Bonferroni test were used to compare the significance between groups. Analyses were performed using the SPSS program (SPSS, Inc, Chicago, Ill).

\section{RESULTS}

Cell viability after isolation of each BMCs preparation used and prior experiment was greater than $95 \%$ in all instances.

\section{Dose-Response Study (Study 1)}

Figure 1, $A$ to $C$, shows that CK release and the percent of cell necrosis and apoptosis seen in the atrial myocardial slices subjected to $\mathrm{I} / \mathrm{R}$ alone were not significantly affected by doses of $1 \times 10^{6} \mathrm{BMCs}$ or less. However, significant reduction in all indexes of injury was observed at a dose of $5 \times 10^{6}$ cells, equivalent to $0.142 \pm 0.006 \times 10^{6}$ cells $/ \mathrm{mg}$ wet myocardium, with no additional improvement at the higher dose.

\section{The Potency of BMCs and the Role of the Time of Administration (Study 2)}

Figure 2, $A$ to $C$, shows that the incubation of atrial myocardial slices with BMCs during the ischemic or reoxygenation period alone was equally effective in reducing myocardial CK release and cell death seen in I/R alone and that the protection observed in the 2 groups was similar to that of BMCs when present during $\mathrm{I} / \mathrm{R}$ and also that of IP.

\section{The Effect of the Source and the Manipulation of BMCs (Study 3)}

The results show that allogenic BMCs reduce the $\mathrm{CK}$ release and cell death seen in the $\mathrm{I} / \mathrm{R}$ alone group to a degree identical to that obtained with autologous BMCs (Figure E1). Figure 3 shows that both methods, the culture (Figure 3, $A$ to $C$ ) and the freezing (Figure 3, $D$ to $F$ ) of allogenic BMCs, significantly reduce $\mathrm{CK}$ release and cell death when compared with $\mathrm{I} / \mathrm{R}$ alone, an effect that again was comparable with the one observed with autologous fresh BMCs.

\section{Preconditioning With BMCs (Study 4)}

As seen in Figure 4, $A$ to $C$, the incubation of atrial myocardial slices with BMCs for 10, 20, and 30 minutes before $\mathrm{I} / \mathrm{R}$ resulted in progressive protection as compared with $\mathrm{I} / \mathrm{R}$ alone, with maximal protection in the 30-minute group, values that were almost identical to those obtained with IP. 

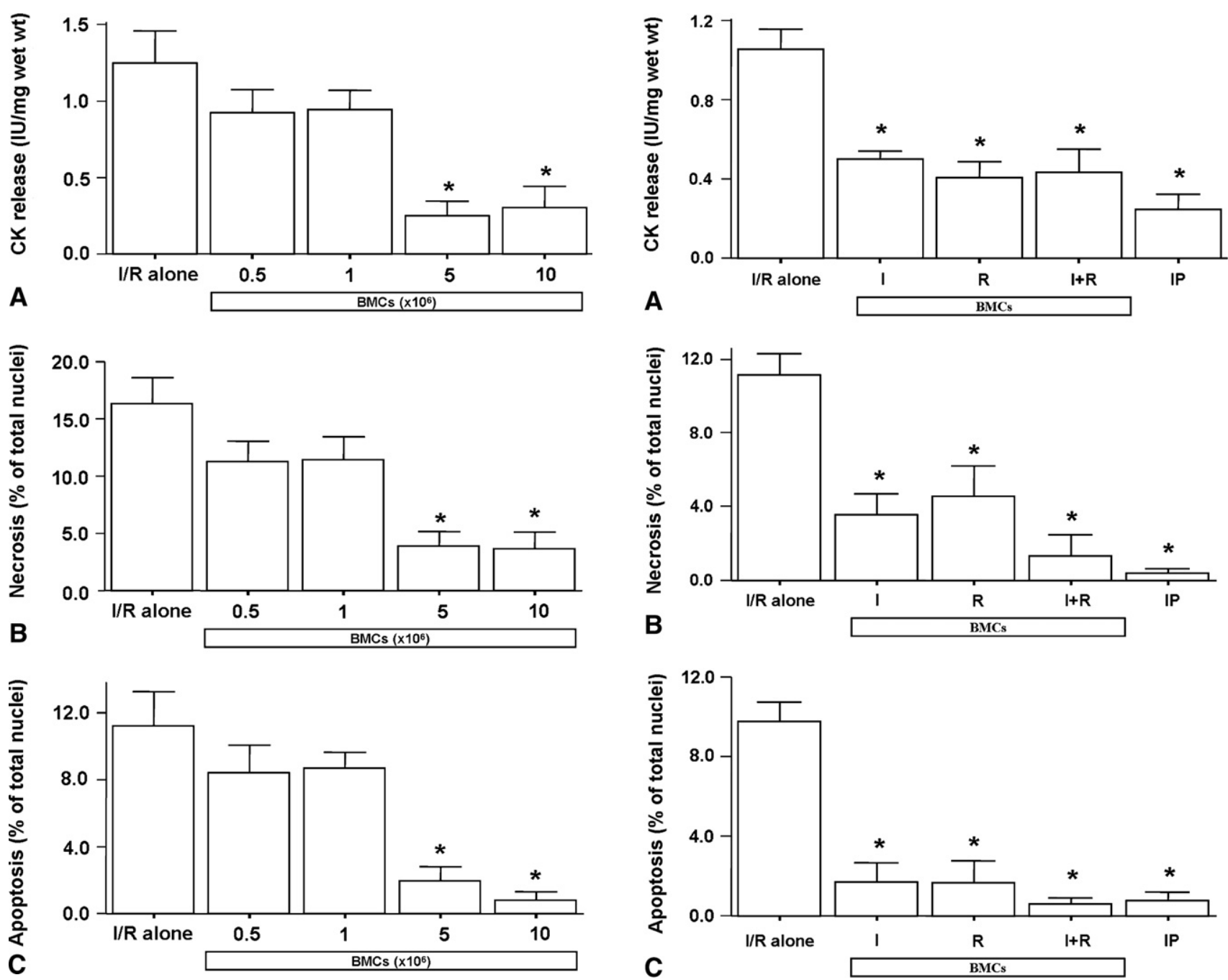

FIGURE 1. Dose-response effect of BMCs on CK release (A) and cell necrosis (B) and apoptosis $(\mathrm{C}) .{ }^{*} P<.05$ versus $\mathrm{I} / \mathrm{R}$ alone. $B M C$, Bone marrow cell; $C K$, creatine kinase; $I / R$, ischemia/reoxygenation.

\section{Preconditioning With Conditioned Media (Study 5)}

Figure 5, $A$ to $C$, shows that the conditioned media significantly reduced CK release and cell death, as compared with $\mathrm{I} / \mathrm{R}$ alone, when coincubated with the atrial myocardial slices for 30 minutes before $\mathrm{I} / \mathrm{R}$. The results were almost identical with those obtained by preconditioning with BMCs (30 minutes) or by IP, suggesting that the observed protective effect is mediated by a factor or factors produced by $\mathrm{BMCs}$ and contained in the conditioned media.

\section{Role of IGF-1R in BMC-Induced Myocardial Protection (Study 6)}

Figure 6, $A$ to $C$, shows that the specific IGF-1R blocker PQ401 at the highest concentration used $(150 \mu \mathrm{mol} / \mathrm{L})$ did not affect CK release and cell death caused by $\mathrm{I} / \mathrm{R}$. It also demonstrates that the favorable effect of the conditioned media was abolished by PQ401 at concentrations of $15 \mu \mathrm{mol} / \mathrm{L}$

FIGURE 2. The potency of myocardial protection by BMCs as compared to ischemic preconditioning (IP) and the role of the time of administration of BMCs on CK release (A), cell necrosis (B), and apoptosis (C). BMC, Bone marrow cell; $C K$, creatine kinase; $I / R$, ischemia/reoxygenation; $I$, BMCs administered during ischemia only; $R$, BMCs administered during reoxygenation only, $I+\mathrm{R}$, BMCs administered during $\mathrm{I} / \mathrm{R}$. ${ }^{*} P<.05$ versus $\mathrm{I} / \mathrm{R}$ alone.

or more, suggesting that IGF-1R is required for the protection induced by BMCs.

IGF-1 and IGF-2 could not be detected by the commercial ELISA kits in the conditioned media at the end of 30 minutes of incubation with BMCs. Because of that, the minimum detectable concentrations for the assays of the 2 factors ( 62.5 $\mathrm{ng} / \mathrm{mL}$ for IGF- 1 and $40 \mathrm{ng} / \mathrm{mL}$ for IGF-2) were used instead of the BMCs and the conditioned media. The results demonstrated that IGF-1 and IGF-2 in combination at a concentration above the level present in the conditioned media by themselves did not significantly affect the $\mathrm{CK}$ release and cell death caused by $\mathrm{I} / \mathrm{R}$ (data not shown), thus suggesting that either factor(s) other than IGF-1 and IGF-2 are acting through the IGF-1R to produce the protective effect or that 

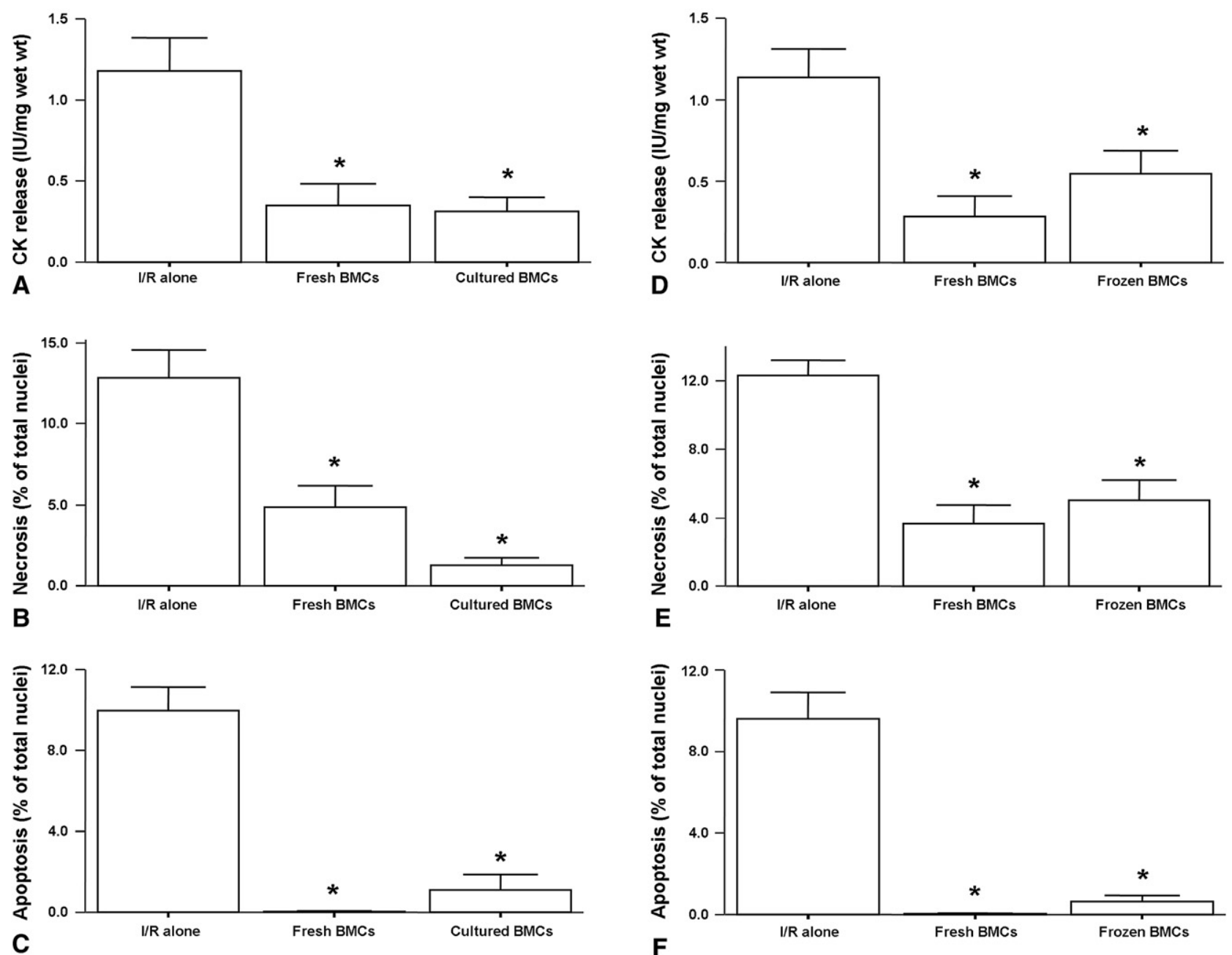

FIGURE 3. The effect of culture (A, B, and C) and freezing (D, E, and F) on the capacity of BMCs to reduce CK release and cell necrosis and apoptosis. $B M C$, Bone marrow cell; $C K$, creatine kinase; $I / R$, ischemia/reoxygenation. $* P<.05$ versus $\mathrm{I} / \mathrm{R}$ alone.

the role of IGF-1 and IGF-2 is necessary but not sufficient to achieve the benefit induced by BMCs and requires the concomitant effect of additional factor(s).

\section{Role of CD133 ${ }^{+}$Cells (Study 7)}

The results demonstrate that although the reduction in CK release and cell death can be replicated by the incubation of the myocardial slices with BMCs for 30 minutes before I/R, the $\mathrm{CD}_{133^{+}}(0.3 \pm 0.04 \% \mathrm{BMCs})$ and $\mathrm{CD} 133^{-}$population failed to significantly modify the mean values for the 3 indexes of injury seen in the I/R alone group (data not shown).

\section{DISCUSSION}

We have demonstrated that the protection of the human myocardium induced by BMCs is mediated through the IGF-1R. Because the protective effect of BMCs cannot be replicated by the combine use of IGF-1 and IGF-2, it is clear that although these factors could be necessary they are not sufficient to induce protection and that other as yet unknown
BMCs-secreted factor(s) are required. In addition, we have elucidated the optimal conditions necessary to obtain maximal benefit, thus opening the door for a more effective clinical application of BMCs.

\section{BMCs and Myocardial Protection}

Our results provide clear evidence on the capacity of BMCs, whose potency is similar to that of IP, to induce protection of the human myocardium by significantly decreasing the death of cells at risk, a finding that is in agreement with our previous results. ${ }^{7}$ Other studies have also suggested that ischemic changes in experimental animal models can be prevented or decreased by BMCs via a paracrine effect. ${ }^{5}$ Therefore, it is possible that the modest improvement in cardiac function seen in some clinical trials using BMCs is due, at least in part, to an early effect that reduces the loss of cells destined to die in the area at risk. Of course, such a mechanism would not exclude the possibility that BMCs may ameliorate cardiac function by late tissue regeneration either via 



FIGURE 4. The effect of preconditioning with BMCs, induced by coincubation of cells with muscles for various time periods before ischemia, on $\mathrm{CK}$ release (A), cell necrosis (B), and apoptosis (C). Some muscles were also subjected to ischemic preconditioning (IP). BMC, Bone marrow cell; $C K$, creatine kinase; $I / R$, ischemia/reoxygenation. ${ }^{*} P<.05$ versus $\mathrm{I} / \mathrm{R}$ alone.

differentiation of the transplanted BMCs or through the stimulation of resident stem cells, although these are two topics that remain the source of intense debate.

Here we have also shown that the myocardial protection of BMCs is dose-dependent but plateaus at about $1.5 \times 10^{5}$ $\mathrm{BMCs} / \mathrm{mg}$ wet myocardium. This means that $71 \times 10^{9}$ (or $\sim 10^{11}$ ) BMCs could be required to obtain optimal protection of a heart weighting $500 \mathrm{~g}$. This is an important finding that may explain the variable results reported by recent clinical trials. ${ }^{2,3}$ It is worth noting that the doses of cells used in these trials were well below the optimal dose seen in our study, and it is possible that the reported benefit was only partial. The argument that the myocardial protection of BMCs is dosedependent is reinforced by the finding that reduced mortality

FIGURE 5. The effect of preconditioning with conditioned media, as compared with BMCs and ischemic preconditioning $(I P)$, on CK release (A), cell necrosis (B), and apoptosis (C). $B M C$, Bone marrow cell; $C K$, creatine kinase; $I / R$, ischemia/reoxygenation. ${ }^{*} P<.05$ versus $\mathrm{I} / \mathrm{R}$ alone.

was seen in patients with established postinfarction heart failure receiving a high number of BMCs. ${ }^{19}$ Moreover, metaanalyses of clinical trials on intracoronary BMC therapy after acute myocardial infarction have also suggested the existence of a dose-response association between injected cell number and left ventricular ejection fraction change. ${ }^{2,3}$ Therefore, the design of future clinical studies must take into consideration the importance of selecting an appropriate dose of BMCs, although it may be possible to speculate that stimulation of BMCs, such as hypoxia, will produce more factors that could compensate for a lower number of cells administered. ${ }^{12}$ Furthermore, the demonstration that less than $5 \%$ of the BMCs administered via the coronary arteries remain in the myocardium is an additional concern that would account for the critical issue of cell dosage. ${ }^{20}$

Another important finding of these studies is that the protection by BMCs can be obtained when cells are applied 

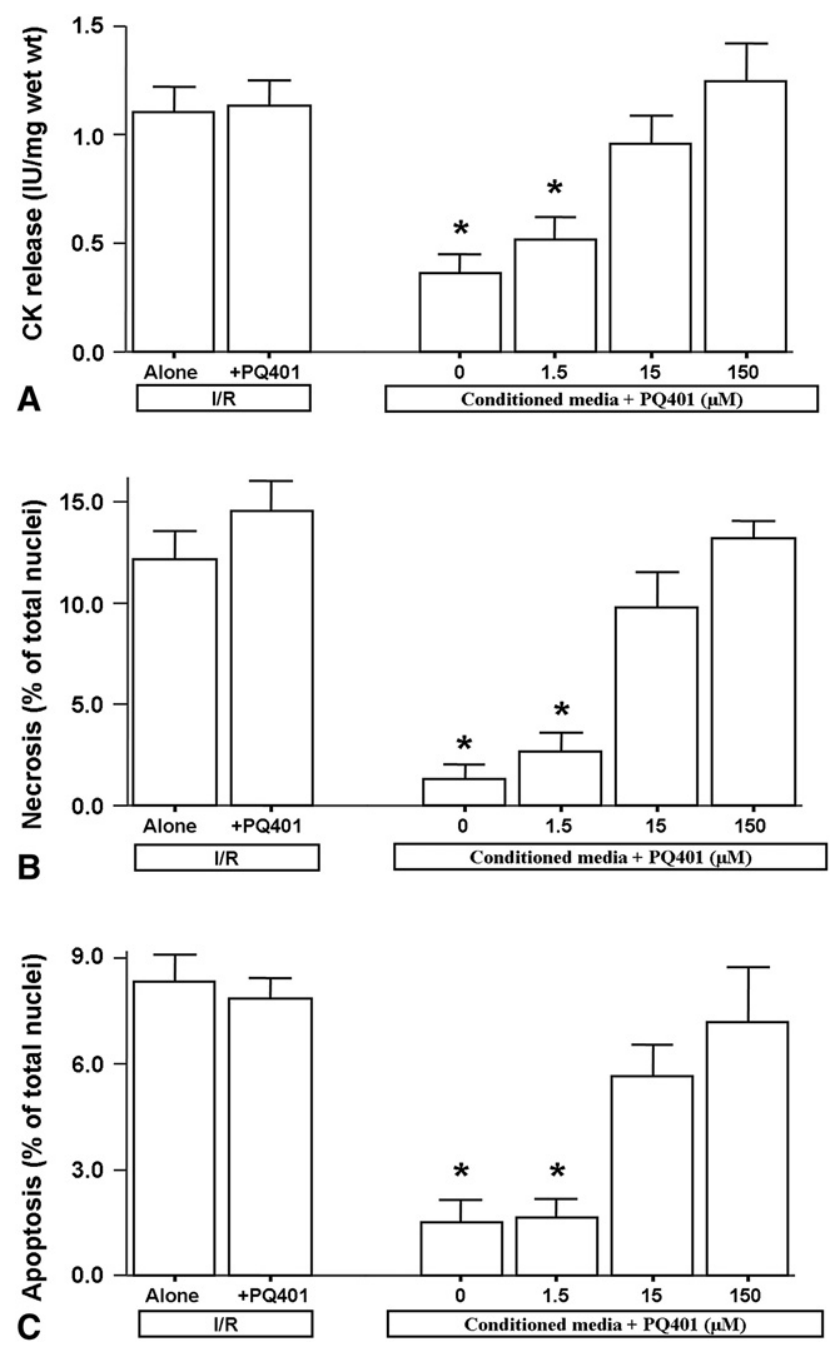

FIGURE 6. The effect of the specific IGF-1R blocker PQ401 at different concentrations in the conditioned media, when coincubated with the muscles for 30 minutes before ischemia, on CK release (A), cell necrosis (B), and apoptosis (C). $B M C$, Bone marrow cell; $C K$, creatine kinase; $I / R$, ischemia/reoxygenation; IGF-R1, insulin-like growth factor-1 receptor. $* P<.05$ versus $\mathrm{I} / \mathrm{R}$ alone.

before or during ischemia or during reoxygenation and that the degree of protection is similar in all instances without further improvement when they are administered at more than one time point. However, it should be noted that in our studies BMCs were administered for the first 2 hours of reoxygenation and that it is not known whether they may be as effective when given at later stages of reperfusion. Indeed, the time of BMC administration after a myocardial infarction has been argued as a key factor to improve cardiac function, ${ }^{21}$ and a clear improvement was claimed in a preliminary report when the BMCs were administered in the first few hours after the myocardial infarction. ${ }^{22}$ Therefore, further studies will be required to characterize the time course of the benefit.

\section{Allogenic BMCs and Effect of Cell Manipulation}

Transplantation of allogenic BMCs has been shown to be feasible and effective clinically ${ }^{23}$; however, the present studies have demonstrated for the first time that allogenic BMCs protect the myocardium against ischemic injury to a degree similar to that of autologous BMCs. They also suggest that allogenic BMCs, being readily available, could be successfully applied in clinical conditions where autologous cells cannot be timely prepared or are defective. It should be conceded that immune reaction remains a considerable problem after allogenic cell transplantation, ${ }^{23}$ but allogenic mesenchymal stem cells, a subset of BMCs, have been reported to engraft without rejection and contribute to heal necrotic tissue. ${ }^{24}$ The results obtained with conditioned media suggest that it might be possible to devise therapeutic approaches that have the advantages of the allogenic cells, such as ready availability at all times, without the potential immunologic drawbacks.

Although manipulation of BMCs by freezing and culturing of cells does not abolish myocardial protection, previously it has been suggested that subtle differences in cell processing and storage may affect the number and functionality of infused progenitor cells that, in turn, could explain the discordance between clinical trials. ${ }^{4}$ We cannot fully explain the discrepancy between these claims and the results reported here. However, whereas the protective effect was investigated in our studies, the capacity to engraft was assessed in the other study. ${ }^{4}$

\section{Mechanism of Action}

We have shown that the protection of the human myocardium by BMCs is mediated by a secreted factor(s) that requires the incubation of cells for at least 30 minutes to sufficiently accumulate in the media to achieve maximal therapeutic efficacy. These results in man are supported by an animal study showing that the use of conditioned media from BMCs significantly increases microvessel density, decreases fibrosis, and prevents apoptosis in the infarcted myocardium, thus leading to improvement in cardiac function. ${ }^{11}$ However, in this experimental study, the conditioned media was obtained after culturing BMCs and then administered directly into the myocardium immediately after coronary ligation and subsequently intraperitoneally at several time points after infarction. ${ }^{11}$

The myocardial protection obtained with BMCs or the BMC-conditioned media was as potent as that of IP. A previous study from our laboratory ${ }^{7}$ demonstrated that the BMC-induced myocardial protection can be abolished by blocking the activation of kinases such as PKC and p38MAPK, both of which have been shown to be integral parts of the signaling transduction mechanism of IP. ${ }^{25}$ These kinases are also downstream effectors of the IGF-1R. ${ }^{26}$ Therefore, it is likely that BMCs and IP are sharing some of the mechanism required to elicit their protective action. 
In the present study, the IGF-1R was identified as a necessary mediator of the myocardial protection induced by BMC-conditioned media since the benefit was completely abolished by the IGF-1R-specific antagonist PQ401 in a dose-dependent manner. This finding would suggest that a factor responsible for the beneficial action of the BMC-conditioned media is IGF, a thesis that would be supported by previous experimental studies on the protective properties of this growth factor. ${ }^{10,27}$ However, IGF-1 and IGF-2 were below the level of detection of the commercial ELISA kit in the BMC-conditioned media, and when both IGFs were used at higher concentrations to those present in the media they were not sufficient to reduce ischemic injury. These results suggest that factor(s) other than IGF-1 and IGF-2 acting through IGF-1R are necessary to induce protection. Given the complex biological actions triggered by the BMCs or their conditioned medium, it seems reasonable that other factors alone or in combination with IGF are needed to produce myocardial protection. Certainly, a full elucidation of the factor(s) responsible for cardioprotection would require further investigation.

In clinical studies, $\mathrm{CD} 133^{+}$cells have been reported to possess regeneration potential ${ }^{18}$ and to promote cardiac recovery after a recent myocardial infarction. ${ }^{16}$ Because of this, and due to its stemness potential, we investigated whether the $\mathrm{CD} 133^{+}$cells in the preparation are responsible for the BMC-induced myocardial protection. Unfortunately, neither the $\mathrm{CD} 133^{+}$nor the remaining BMC population was able to reduce ischemic injury. This suggests that cell separation by magnetic immunobeads impairs the capacity of cells to secrete the factor(s) accountable for the reduction in ischemic injury.

\section{LIMITATIONS}

A limitation of our studies is the use of atrial tissue, inasmuch as it may not fully represent the response of ventricular myocardium. Nonetheless, recent studies in our laboratory (unpublished data) have shown that the degree of injury induced by $\mathrm{I} / \mathrm{R}$ of the human atrial myocardium is similar to the one observed in muscles from the left ventricle of mice and rats, suggesting that the response of the atrial and ventricular myocardium to $\mathrm{I} / \mathrm{R}$ is comparable. In addition, we (unpublished data) and other investigators ${ }^{28}$ have shown that a comparable level of protection occurs with preconditioning in atrial and ventricular myocardium. Another potential limitation may be that all the studies were performed in an in vitro preparation that is devoid of blood components. However, the latter shortcoming could also be advantageous to examine the direct relationship between the intervention and the myocardium, removing the potential confounding effects of blood and vasculature. Despite the above considerations, caution must be taken when extrapolating the present results to clinical conditions.
We acknowledge Ms Lakshmi Srinivasan, Ms Wendy Rathbone, and Mrs Nicola Harris for their help, and also the Take Heart Leicester and Glenfield Hospital Cardiac Surgery Theater for their assistance.

\section{References}

1. Ang KL, Chin D, Leyva F, Foley P, Kubal C, Chalil S, et al. Randomized, controlled trial of intramuscular or intracoronary injection of autologous bone marrow cells into scarred myocardium during CABG versus CABG alone. Nat Clin Pract Cardiovasc Med. 2008;5:663-70.

2. Lipinski MJ, Biondi-Zoccai GG, Abbate A, Khianey R, Sheiban I, Bartunek J, et al. Impact of intracoronary cell therapy on left ventricular function in the setting of acute myocardial infarction: a collaborative systematic review and meta-analysis of controlled clinical trials. J Am Coll Cardiol. 2007;50:1761-7.

3. Martin-Rendon E, Brunskill SJ, Hyde CJ, Stanworth SJ, Mathur A, Watt SM. Autologous bone marrow stem cells to treat acute myocardial infarction: a systematic review. Eur Heart J. 2008;29:1807-18.

4. Seeger FH, Tonn T, Krzossok N, Zeiher AM, Dimmeler S. Cell isolation procedures matter: a comparison of different isolation protocols of bone marrow mononuclear cells used for cell therapy in patients with acute myocardial infarction. Eur Heart J. 2007;28:766-72.

5. Gnecchi M, Zhang Z, Ni A, Dzau VJ. Paracrine mechanisms in adult stem cell signaling and therapy. Circ Res. 2008;103:1204-19.

6. Kocher AA, Schuster MD, Szabolcs MJ, Takuma S, Burkhoff D, Wang J, et al Neovascularization of ischemic myocardium by human bone-marrow-/derived angioblasts prevents cardiomyocyte apoptosis, reduces remodeling and improves cardiac function. Nat Med. 2001;7:430-6.

7. Kubal C, Sheth K, Nadal-Ginard B, Galiñanes M. Bone marrow cells have a potent anti-ischemic effect against myocardial cell death in humans. $J$ Thorac Cardiovasc Surg. 2006;132:1112-8.

8. Zhang JG, Ghosh S, Ockleford CD, Galiñanes M. Characterization of an in vitro model for the study of the short and prolonged effects of myocardial ischaemia and reperfusion in man. Clin Sci (Lond). 2000;99:443-53.

9. Ghosh S, Standen N, Galiñanes M. Preconditioning the human myocardium by simulated ischemia: studies on the early and delayed protection. Cardiovasc Res. 2000;45:339-50.

10. Buerke M, Murohara T, Skurk C, Nuss C, Tomaselli K, Lefer AM. Cardioprotective effect of insulin-like growth factor I in myocardial ischemia followed by reperfusion. Proc Natl Acad Sci U S A. 1995;92:8031-5.

11. Takahashi M, Li TS, Suzuki R, Kobayashi T, Ito H, Ikeda Y, et al. Cytokines produced by bone marrow cells can contribute to functional improvement of the infarcted heart by protecting cardiomyocytes from ischemic injury. Am J Physiol Heart Circ Physiol. 2006;291:886-93.

12. Uemura R, Xu M, Ahmad N, Ashraf M. Bone marrow stem cells prevent left ven tricular remodeling of ischemic heart through paracrine signaling. Circ Res. 2006; 98:1414-21.

13. Vogt AM, Htun P, Kluge A, Zimmermann R, Schaper W. Insulin-like growth factor-II delays myocardial infarction in experimental coronary artery occlusion. Cardiovasc Res. 1997;33:469-77.

14. Xu M, Uemura R, Dai Y, Wang Y, Pasha Z, Ashraf M. In vitro and in vivo effects of bone marrow stem cells on cardiac structure and function. J Mol Cell Cardiol. 2007;42:441-8.

15. Gable KL, Maddux BA, Penaranda C, Zavodovskaya M, Campbell MJ, Lobo M, et al. Diarylureas are small-molecule inhibitors of insulin-like growth factor I receptor signaling and breast cancer cell growth. Mol Cancer Ther. 2006;5:1079-86.

16. Bartunek J, Vanderheyden M, Vandekerckhove B, Mansour S, De Bruyne B, De Bondt $\mathrm{P}$, et al. Intracoronary injection of CD133-positive enriched bone marrow progenitor cells promotes cardiac recovery after recent myocardial infarction: feasibility and safety. Circulation. 2005;112(9 Suppl):I178-83.

17. Goussetis E, Manginas A, Koutelou M, Peristeri I, Theodosaki M, Kollaros N et al. Intracoronary infusion of CD133+ and CD133-CD34+ selected autologous bone marrow progenitor cells in patients with chronic ischemic cardiomyopathy: cell isolation, adherence to the infarcted area, and body distribution. Stem Cells. 2006;24:2279-83.

18. Stamm C, Kleine HD, Westphal B, Petzsch M, Kittner C, Nienaber CA, et al $\mathrm{CABG}$ and bone marrow stem cell transplantation after myocardial infarction. J Thorac Cardiovasc Surg. 2004;52:152-8.

19. Assmus B, Fischer-Rasokat U, Honold J, Seeger FH, Fichtlscherer S, Tonn T, et al. Transcoronary transplantation of functionally competent BMCs is associated with a decrease in natriuretic peptide serum levels and improved survival of 
patients with chronic postinfarction heart failure: results of the TOPCARE-CHD Registry. Circ Res. 2007;100:1234-41.

20. Hofmann M, Wollert KC, Meyer GP, Menke A, Arseniev L, Hertenstein B, et al. Monitoring of bone marrow cell homing into the infarcted human myocardium. Circulation. 2005;111:2198-202.

21. Bartunek J, Wijns W, Heyndrickx GR, Vanderheyden M. Timing of intracoronary bone-marrow-derived stem cell transplantation after ST-elevation myocardial infarction. Nat Clin Pract Cardiovasc Med. 2006;1(3 Suppl):S52-6.

22. Huang R, Yao K, Qian J, Ge L, Li Y, Niu Y, et al. Emergency intracoronary stem cell transplantation in patients with acute myocardial infarction (TCT-STAMI-2): Long-term outcome. Circulation. 2008;118(Suppl 2):S791 (Abstract).

23. Messner HA. Long-term outcome of allogeneic transplants in acute myeloid leukemia. Leukemia. 2002;16:751-2.

24. Amado LC, Saliaris AP, Schuleri KH, St John M, Xie JS, Cattaneo S, et al. Cardiac repair with intramyocardial injection of allogeneic mesenchymal stem cells after myocardial infarction. Proc Natl Acad Sci U S A. 2005;102: 11474-9.

25. Loubani M, Galiñanes M. Pharmacological and ischemic preconditioning of the human myocardium: mitoKATP channels are upstream and p38MAPK is downstream of PKC. BMC Physiol. 2002;2:10-23.

26. Vincent AM, Feldman EL. Control of cell survival by IGF signaling pathways. Growth Horm IGF Res. 2002;12:193-7.

27. Li Q, Li B, Wang X, Leri A, Jana KP, Liu Y, et al. Overexpression of insulin-like growth factor-1 in mice protects from myocyte death after infarction, attenuating ventricular dilation, wall stress, and cardiac hypertrophy. J Clin Invest. 1997;100: 1991-9.

28. Speechly-Dick ME, Grover GJ, Yellon DM. Does ischemic preconditioning in the human involve protein kinase $\mathrm{C}$ and the ATP-dependent $\mathrm{K}+$ channel? Studies of contractile function after simulated ischemia in an atrial in vitro model. Circ Res. 1995;77:1030-5. 



FIGURE E1. The effect of allogenic BMCs as compared with autologous BMCs on CK release (A) and cell necrosis (B) and apoptosis (C). BMC, Bone marrow cell; $C K$, creatine kinase; $I / R$, ischemia/reoxygenation. $* P<.05$ versus $\mathrm{I} / \mathrm{R}$ alone. 